\title{
A Study of the Demand for Fiber Fabrics of Chinese Elderly Clothing Market
}

\author{
Fan-yao NIE \\ College of Fashion and Design, \\ Donghua University \\ Shanghai, China \\ ypnypj@163.com
}

\author{
Yu-mei CUI* \\ College of Fashion and Design, \\ Donghua University \\ Shanghai, China \\ cymyhyez@126.com
}

\begin{abstract}
Along With the accelerating aging process of china, the number of the elder continues to increase, and the development of the elder garment industry is imminent. However, with the rapid development of science and technology, the fabric of elder clothing is still unable to satisfy the actual needs of consumers. This thesis introduces the current status of the elderly population first, meanwhile lists the existed problems in the present elder clothing market, focuses on analysis of the health, comfort and security of the fabric, such as the fabric dye safety, the sterilization and the heat preservation, and put forward selfviewpoint of fiber fabric properties in the market. Moreover, the thesis summaries and analyzes the future development trend of the elderly clothing fabric, to lay foundations for the future development of the "silver market".
\end{abstract}

Keywords-aging; the elder clothing fabric; fiber fabric properties; the future development trend of the fabric

\section{INTRODUCTION}

Clothing, food, housing, and transportation are four basic necessities of human life. Clothing, as a very important necessity, is no longer limited to the traditionally basic function of keeping warming. With the development of technology and upturning of living standard, people are demanding for a much higher level of functionality of clothing which tends to be more environmentally friendly, healthy, and technological. Nowadays, China has been gradually developing to an aging country. More and more enterprises and merchants are focusing on the elderly clothing market which contains unlimited business opportunities and potentials. The elderly clothing market really has broad developing space. But there is always a serious problem-the old regard clothing materials as the most important thing when they are shopping, but the existing materials cannot meet their needs. And the problem of clothing materials cannot be solved which causes the situation that "the old cannot buy satisfying clothing" and "the seller cannot sell their clothing". As a result, it is very necessary to conduct a further study of the elderly clothing materials.

\section{The CurRent Situation AND Problems of ELDERLY CLOTHING MARKET IN CHINA}

\section{A. The Current Situation of Aging Population in China}

According to the statistics, in the year of 2000, the proportion of people who are over 60 years old exceeded $10 \%$ of the global population, which means the whole world has entered the aging stage (According to the international convention, the proportion of people over 60 years old exceeding $7 \%$ is counted as the aging society). As a populous nation, China is one of the developing countries who enter the aging stage earlier with a $3.2 \%$ average growth rate of people over 60 years old. This rate equals 3 times of our country's natural population growth rate, and is far more than the $2.4 \%$ global elderly growth rate. Until 2005, China's elderly people reached 150 million, and by the end of 2013, the number of China's elderly people easily broke through 200 million. It's estimated that by 2020, our country's elderly people will reach 248 million, accounting for $17 \%$ of the total population. A conservative estimate indicates that by 2050, China's elderly people will reach $31.1 \%$, which means one fourth of Chinese is an elderly people.

\section{B. The Current Situation and Problems of Elderly Clothing Market in China}

At present, China has a population of two hundred million aging people, and those people are a large consumption group. According to the statistics, Chinese marketing will require over a billion suits of elderly clothing, which will create 120 billion outputs. But now, the annual value is only 50 billion. Is that the low purchasing power of aging people or the low quality of products causes the marketing sluggishness? That is a problem which needs our deeply reflection.

There are a series of problems that prevent the development of the elderly clothing market, such as the safety of materials, category shortage, old fashion styles, and color limitation. Recently, the problem of elderly clothing materials is becoming more and more urgent. Consumers also care most about this problem. The old will have biogenic changes in both physical and psychological aspects with age--the decrease of body function leads to lots of elderly integrated symptoms. On one hand, they will have mental fatigue and slow reaction, which make them have no enough energy to do much washing. On the other hand, their metabolic capabilities decrease, which causes the loss of heat. So they are more sensitive to climate changes and easily catch colds. Furthermore, the old have slowly reaction and behaviors. They cannot escape from emergencies immediately such as fires. So we need to take good advantages of clothing materials to benefit the aging people for the reasons above and so on.

\section{The CURRENT SituAtion AND DEVELOPMENT OF ELDERLY CLOTHING MATERIALS}

The initial clothing materials in China are fabrics of kohemp, ramie, and cordettes. Because the ko-hemp and 
cordettes have a good property of moisture permeability, breathability, and heat dissipation, they have the highest value in the summer clothing materials for aged people. Meanwhile, from time immemorial, China has been having the title of "the silk country". On account of thin, silky, shiny and beautiful, silk is the best fabrics for outerwear and underwear of elderly clothing. In addition, in the world of animal furs, woolen fabric is the best choice of material for elderly people in autumn and winter because it is comfortable and flexible, also has good heat retention. Cotton fabric has good moisture permeability, but it is easily to fold. So it's used to make sportswear and other elderly body fitted clothing. In the second half of the 19th century, chemical fabrics was introduced and very popular in China because it's durable, crease resistant and easily to manage. Nowadays, in the 21st century, elderly clothing market is still based on the principal of natural, comfortable and moisture permeability. Therefore, the traditional cotton, hemp, silk, wool and other natural fiber fabrics still dominate the market and perennially favored by the elder consumers. However, on the basis natural fiber, the development of fabrics constantly changed with the demand of human life changing.

\section{A. Modification of Natural Fiber Fabrics}

Natural fiber fabrics have been warmly welcomed by most consumers. But with the development of technology and living quality, some processed materials which are the transformation of wool and other natural fiber fabrics appear in the current market. The processing technologies such as low-pollution, low chlorination, low-temperature plasma, enzyme, and stretching can improve the properties of wool so as to improve its value. Similarly, those technologies are also applied to the transformation of natural silk fabrics' properties. Through processing biological enzymes of cotton, hemp, silk, and wool, these fabrics will be improved significantly in terms of appearance, performance, and using value.

\section{B. Safety of Colorants}

Nowadays, the old are more and more concerned about health with age. The majority of them regard the safety of materials as the most important criterion when choosing clothing. But in the current market, there are many cases of using unsafe materials exposed. These unsafe materials include carcinogenic fabrics, fluorescent brighteners, unqualified colorant-benzidine azo dye and high content of formaldehyde. These unsafe problems seriously attack the physical and mental health of the old. Therefore, for the elderly market, especially for those who have weaker body resistance, fabric suppliers should pay more attention to the safety of fabrics, and the regulatory authorities should also increase the quality of the supervision for fabrics.

\section{Fibers with Functions of Anti-bacterial and Deodorizing}

The immunity of elderly people is decreasing. As a result, they are prone to be infected by bacteria. At the same time, their endocrine disorders can easily lead to incontinence. That is to say, they can't effectively control the normal discharge of waste. When such actions which can increase abdominal pressure such as sneezing or coughing appear, it is easily to cause incontinence phenomenon which lead to lots of troubles for the normal life of the old. For those people, clothing especially fitted clothing must have a good property of deodorizing and anti-bacteria to prevent the propagation and regeneration of bacteria and fungi. Otherwise, it will cause a serious result. In addition, fibers with functions of antibacterial and deodorizing can greatly prevent the attack of allergies, skin diseases, asthma and other diseases.

\section{Fibers with Functions of Heat Storage and Dissipation}

The old have weak ability to adapt to the outside temperature, so their body heat is easily to dissipate. In summer, the outdoor high temperature can easily cause heat strokes. And in winter, the old can easily catch cold due to wet and cold climate. So the materials must have the property of heat storage and dissipation. When ambient temperature changing, the fabrics can absorb and release heat accordingly to keep skin at a constant state of heat. In some way, the fabrics can form a micro-climate between skin and clothing by this function to regulate body temperature. It is easy for the fabrics with poor hygroscopicity and ventilation to produce static electricity and bacteria. But this kind of fabric was created with a double structure of skin-core, so its dehumidification rate is 2 to 3 times of cotton. Its relative density is $30 \%$ smaller than synthetic fiber. So it is more skinfriendly, absorbent, and breathable. In addition, this kind of fiber can not only be purely spanned, but also be blended with natural fibers for the production of sportswear and fitted clothing. So it can efficiently help the old adapt to the discomfort caused by temperature changes.

\section{E. Fire-retardant Fibers}

The old move very slowly. When fires and other emergencies occur, it is difficult for them to escape quickly. So it is necessary to apply fire-retardant fibers to elderly clothing and related textile products. Fire-retardant fiber is a safe, non-toxic, and renewable fiber. Its limiting oxygen index is greater than $28 \%$ which has a good function of flame retardant. Once ignited, it can be self-extinguished without sustained fire burning phenomenon and melting drippings. Meanwhile, the fire-retardant fiber has characters of comfortable, good hygroscopicity and ventilation. It should be widely applied to elderly clothing and textiles in the soon future.

\section{ANAlysis OF THE DEVELOPING TREND OF ELDERLY CLOTHING MATERIALS}

It is estimated that after ten years when the middle-aged people who are now 50 years old enter 60 years old, the purchasing power of the elderly clothing market will greatly increase. These people's pensions will be greatly improved compared with the current situations. In addition, because these groups of people are the first generation of the one-child parents, they have a stronger economic capacity to make consumption decisions. Therefore, the will have a more strict requirements for clothing especially for the clothing materials. According to the needs of the elderly lifestyles, the developing trends of fabrics in the future will be as followed. 


\section{A. Green, Environmental Protection, and Sustainable Development}

Scientific and technological progress has brought convenience to life, and catastrophic damage to environment at the same time. The residual toxic ingredients of fabrics which are harmful to human body have aroused widely concern in society. In order to solve this problem, people spend more efforts on fiber fabrics' effects on human health and environmentally sustainable development, including the raw materials, production, resource recycling, and inspection throughout the production and using process. Environmental fabrics generally refer to those which are natural with lowcarbon and energy, no harmful substances, and recycled. The current trends are as below:

Fiber fabrics with no pollution in the production processes. For example, colored cotton fiber, chitin fiber, apocynum fiber and other organic natural fibers (which have not been contaminated at least three year in the growth process);

Biodegradable fibers. For example, bamboo fiber, tencel fiber, soybean protein fiber and other biodegradable synthetic fiber;

Natural mineral colors, plant-dye fiber;

Photochromic and thermochromic fabric Fabrics: Fabrics made of light-sensitive and thermochromic fibers. The fabrics can change according to the external changing of the amount of light to deliver a special visual sense. And there is another kind of multilayer composite fiber: it takes advantages of lights' refraction to form multi-colors so as to avoid the pollution of dyeing.

\section{B. Technologically Functional Fiber Fabrics}

With the rapid development of technology, the functions of clothing materials have been steadily progressing. But all the products are aiming to meet the physical and psychological needs of the elderly people such as falls prevention materials. The elderly are walking dilatorily and easily to fall down. Once falling down and there is no other family members around, the consequences will be serious. Therefore, the clothing materials with protecting functions are needed to ensure the security of the old. We can use the materials with gel-functional which can deform freely in normality. Once attacked by strong impact force, the gel molecules inside will function to take the force off. At the same time, this material can be appropriately used in human body to reduce the chance of injury, such as hip, knee, elbow and other parts which are easily to touch the ground when people fall down. To image that, in the future functional fibers can also change colors according to the temperature of human body, so that the family members can know the temperature characteristics of the old easily. Or apply reflective materials to fibers, so that it can display normal color in sunlight and reflect strong lights under lamplight in the so as to protect the old from traffic accidents.

\section{Health Caring Eco-fiber Fabrics}

The previously mentioned protein fibers, bamboo fiber, apocynum fiber and chitin fiber are not only environmental protection, but also heat caring to the old.
Protein fiber is raw protein materials extracted from milk, soybeans, corn and other natural objects. Because it is skinfriendly and containing essential amino acids for human bodies, it is health-caring to human skins;

Bamboo fiber contains a strong antibacterial element "bamboo kun". It has anti-bacterial and deodorant functions. Moreover, the fiber pectin and cellulose in bamboo fiber can nourish skins, relieve fatigue, and block ultraviolet rays;

Apocynum fiber is always called 'the king of wild fiber'. It can relieve high blood pressure, high cholesterol, and bronchitis. Also it helps to promote cell viability and resist ultraviolet ray;

Chitin fiber is natural high-fiber substances extracted from crustacean bodies. It is anti-cancer and anti-inflammatory. Furthermore, it can do desensitize to stop bleeding and promote wounds healing. Additionally, it has the antistatic function;

Anion fiber can release negative oxygen ions which lead active Sanso of body to disappear so as to promote microcirculation, eliminate fatigue, activate cells, and enhance immunity;

Medicinal plant dyeing: the used dyeing plants have medicinal functions. It both has the advantages of plants dyeing and functions of health care which dyes do not have. Once the technology is mature and stable, it will have a very high level usage.

\section{SUMMARY}

With the rapid development of the garment industry and improvement of consuming level, the elderly clothing market is developing in a diversified and multi-level direction. In addition, the physical functions of the elder are declining as getting older, which leads to the fiber fabrics dominating the elderly clothing market. To meet the physical and psychological demands of the elder, the fabrics must have better properties such as safety, technology and health caring. The development of fiber fabric reflects the progress of society, the improvement of living standard, and the rapid acceleration of technology. When developing new fiber fabrics, we should advocate those fabrics which have the properties of Chinese characteristics such as people-oriented, sustainable developing, environmental friendly and healthy. This will not only benefits the sustainable development of China's elderly clothing market, but also, to some extent, promotes the progress of the entire textile and garment industries in order to realize the harmonious coexistence of human society and natural environment.

\section{ACKNOWLEDGMENTS}

This work is supported by etc, etc. Work partially supported by grant 2-4570.5 of the Swiss National Science Foundation.

\section{REFERENCES}

[1] Li Hui. Study of the Humanized Clothing Design for the Old People, Qiqihar University, 2012.

[2] Bichen Wang. Importance of the application of green material in clothing design, Tianjin University of Science\& Technology, 2013. 
[3] Gengsheng Chen. The Application and Analysis of the Functional Clothing in the Elderly, South China University of Technology, 2014

[4] Wenjuan Wang. The application of the functional clothing designing in elder clothing. Art Education.12 (2014) 301-302.
[5] Yahong Wu. The Requirements Analysis of Clothes for Aged People to New Fiber, China Textile Leader.12 (2013) 40-41. 